\title{
Factors affecting the intention of sustainable agriculture practices among pepper farmers in Sarawak, Malaysia
}

\author{
Semuroh, J. and *Sumin, V. \\ Fakulti Perladangan dan Agroteknologi, Universiti Teknologi MARA Cawangan Sabah, Kampus Kota \\ Kinabalu, Locked Bag 71, 88997 Kota Kinabalu, Sabah, Malaysia
}

\author{
Article history: \\ Received: 16 April 2021 \\ Received in revised form: 19 \\ June 2021 \\ Accepted: 1 December 2021 \\ Available Online: 12 \\ December 2021
}

\section{Keywords:}

Sustainable,

Agriculture Practice,

Pepper farmers,

Sarawak

DOI:

https://doi.org/10.26656/fr.2017.5(S4).005

\begin{abstract}
The demand for safe, hygienic, organic, and high-quality food products nowadays puts pressure on farmers to produce and practice sustainability. Sustainable agriculture practices (SAPs) are crucial to be implemented on every farm that produced foods to enable the supply of hygienic, safe food products and as a solution of pesticide-residue problems towards a healthier lifestyle. However, the farmers' main challenges towards sustainability and hindering their penetration to the global market are the difficulties in complying with the international standard of quality and certification compliance, such as MyGAP or Malaysian Good Agricultural Practices in cultivating, harvesting, and processing. MyGAP compliance showed that farmers are moving towards sustainable agriculture. This paper was aimed to assess the perception and the factors that influence the Intention to implement SAPs in pepper cultivation among pepper farmers in Sarawak. Descriptive analysis and factor analysis were used to accomplish the objectives of this study. Data collection was through interviews using a structured questionnaire administered on registered farmers under the Malaysian Pepper Board (MPB), planted at least 1 hectare or 2000 pepper trees in Bau and the District of Serian, Sarawak. Systematic stratified random sampling method was used based on the two different districts selected as stratification. The Theory of Planned Behaviour (TPB) was used as the conceptual framework to explain the farmers' behaviour towards SAPs. The results discovered four latent factors influencing Intention to practice SAPs: attitude, subjective norms, perceived behavioural Intention, and Intention, with the value of percentages of variance, explained $13.554 \%, 27.912 \%, 12.506 \%, 8.771 \%$, and $7.703 \%$, respectively. Subjective norms showed a high value of alpha at 0.935 , followed by attitude (0.817) and Intention towards Sustainable Agriculture Practices (0.804). The findings provided the pepper farmers with invaluable insight on the advantages of adopting sustainable agriculture practices to expand their business locally and intentionally.
\end{abstract}

\section{Introduction}

The demand for pepper-based culinary products has increased globally. It became a key condiment for spices mixed called 'baharat' in the middle east. The French prefer white pepper, which is then used in cream-based sauces. Besides culinary, pepper was used for traditional medicinal purposes. Pepper is also known as an aromatic plant because of its antioxidant, antimicrobial, carminative, and antiseptic properties. In conventional practices, pepper is used to relieve pain, atrophic arthritis, apathy, influenza, and febricity, and as a nerve tonic, antibacterial agent, stimulant, digestive, and antitoxin (Hossein et al., 2014).

The consumption of pepper worldwide has been increased from year to year, thus, forces the producer, mainly, farmers to cultivate more pepper to fulfil the global demand. The producers of pepper need to be aware of this situation by improving pepper-produce productivity; consumers demand pepper products of the highest quality. Therefore, it is also crucial to produce pepper that meets the standard and specification of quality products to be hygienic and safely consume Future Market Insight (Future Market Insight, 2014).

Nowadays, pepper is cultivated in many countries. Brazil, India, Indonesia, Malaysia, Vietnam, and Sri Lanka were major producers of pepper globally and registered as members of the International Pepper Community (IPC). IPC is an intergovernmental 
organization of pepper-producing countries that was established in 1972. Thus, to increase pepper production in Malaysia, pepper farmers need to ensure a sufficient supply and the quality of pepper meets the standard to penetrate the global market.

Unprecedented challenges further influence the agricultural sector in Malaysia due to increasing awareness of environmental sustainability and green consumerism concerns at the global and national levels. The long-run ability of the industry to continue contributing to the socio-economic development of the nation, especially the rural economy, might be impeded without comprehensive adaptation strategies (Jamal and Yaghoob, 2014). Malaysia has succeeded in increasing the production of agricultural products. However, both consumers and producers realized that food production is progressively harming the environment and public health. This problem has become a severe concern to consumers today as they are more educated and prefer hygienic and safe products for their health. Consumers' ethics' consumption was influenced by higher income, urbanization, demographic shifts, improved transportation, and consumer perceptions of product quality and safety. Therefore, the agriculture sector, particularly, farmers are responsible for managing its products sustainably and environmentally friendly to ensure product quality and safety (Kusairi and Fatimah, 2009).

The Theory of Planned Behaviour (TPB) was developed from the Theory of Reason Action proposed by (Ajzen, 1985). According to Andrius (2013), as a primary basis of TPB, behavioural intentions are used to forecast a person's actual behaviour. TPB is often applied to theoretical frameworks to portend and understand human behaviour (Kaiser et al., 2005). Arvola et al. (2008) found that individuals who are more sensible about environmental issues are more likely to perform environmentally-friendly behaviour. Thus, the Theory of Planned Behaviour was used to investigate the fundamental measurements in every determinant, such as attitude, subjective norm, and perceived behavioural control and Intention among the pepper farmers towards implementing sustainable agriculture practices in pepper cultivation Sarawak. According to Ajzen (2005), people intend to execute a behaviour in three manners when they appraise it positively or when they experience social pressure to perform it or believe that they have the means and chance to do so. This view of motivation likely accounts for the critical factors that influence farmers' behaviour. Thus, it will form the theoretical basis for explaining the factors that influence farmers' Intention to implement sustainable agriculture practices in Sarawak. This Theory is often applied to theoretical frameworks to portend and understand human behaviour (Kaiser et al., 2005). Arvola et al. (2008), found that individuals who are more sensible about environmental issues are more likely to perform environmentally-friendly behaviour. Thus, this study was conducted to investigate the factor's intention of pepper farmers in terms of their attitudes, pressure from the social aspects, and perceived behavioral control towards implementing sustainable practices in pepper cultivation.

\section{Materials and methods}

\subsection{Sample and questionnaire}

A systematic stratified random sampling method was used in this study, and 203 respondents were interviewed face-to-face using a structured questionnaire consisting of statements addressing and measuring the components of respondents' socio-economic, demographic profile, knowledge, and awareness. The questionnaire comprises three parts; Part A, Part B, and Part C. The Theory of planned behaviour was applied to guide the research.

The study's target population was the pepper farmers from two districts (District of Bau and District of Serian) located in the Kuching area. Each district has the parts; Bau-Opar, Tasik Biru, Serembu, and SerianMuara Tuang, Tarat, Balai Ringin. These locations were selected for this study because they have the most pepper farmers. Data were collected based on farmers registered under the Malaysian Pepper Board (MPB), who planted at least 1 hectare with 2000 pepper trees.

Systematic stratified random sampling method was used based on the two different districts selected as stratification. According to Singh and Masuku (2014), the systematic stratified random sampling method is a sampling method in which a population mutually certain groups known as strata. Then simple random samples are used to select the individuals for each stratum. Each unit of the stratum creates an equal probability of being selected in the sample. The proportion of stratified sampling to obtain a more representative sample in the study. Systematic stratified random sampling provides a more representative cross-section of the population and requires less time and money for the study. The sample size selected using Krejcie and Morgan (1970) formula has been conducted to indicate this study's actual sample size to gain a more accurate result.

The questionnaire was divided into three sections and was measured by a 7-point Likert scale and openended questions. Section A consists of questions about the farmers' socio-demographic information, such as gender, age, ethnicity, religion, marital status, educational background, income status, farming experience, farm size, land ownership, and types of 
pepper planted. Section B examined the farmers' knowledge and environmental awareness about SAPs. Section C is further divided into four parts. The first part comprises questions about farmers' perceptions and attitudes towards SAPs. The second part consists of questions about particular attitudes or consequences of society (e.g., family, friends, relatives) towards farmers' performance or behaviour. Part three explored the farmers' perceived behavioural control, which refers to factors that make the farmers' behaviour is easier or difficult to perform.

In order to accomplish the objectives of this study, descriptive analysis and factor analysis were used to analyse information gathered from the questionnaires. Descriptive analysis was used to summarise the data for each section. While, Meanwhile, factor analysis was used to identify the underlying factor influencing the farmers' Intention (subjective norms and perceived behavioural control) towards SAPs.

\subsection{Conceptual framework}

The Theory of Planned Behaviour (TPB) is used as the conceptual framework to assess the perception and the factors that influence the Intention to implement SAPs in pepper cultivation among pepper farmers in Sarawak. TPB postulates that three independent variables influence an intention: attitude, subjective norms, and perceived behavioral control (Ajzen, 2002), as indicated in Figure 1.

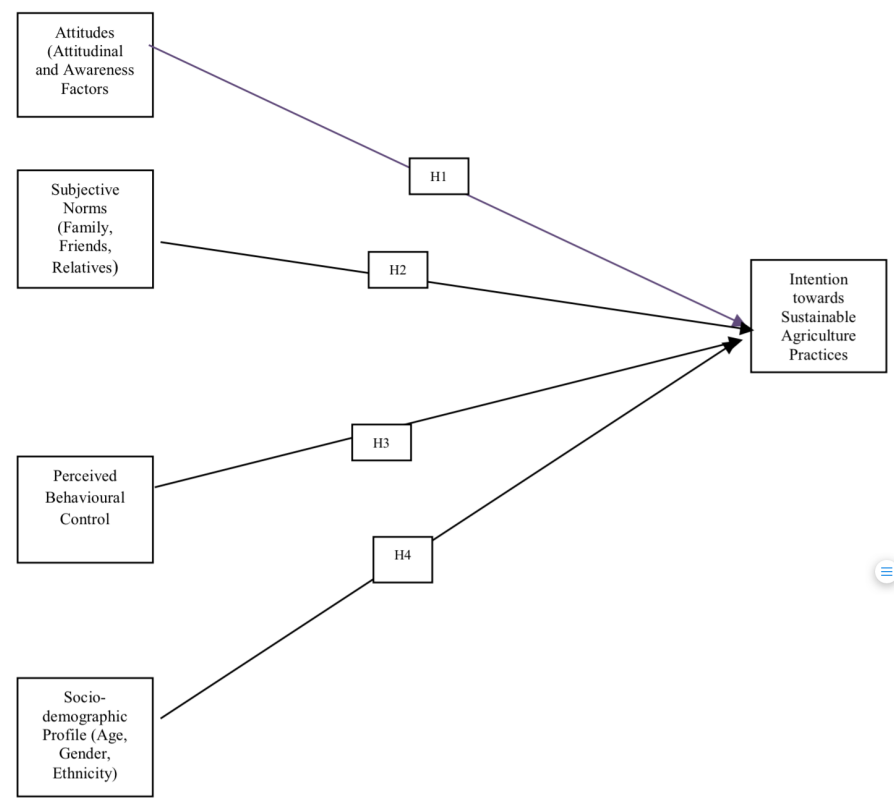

Figure 1. Conceptual framework of the Theory of Planned Behaviour (Sources: Ajzen, 2002)

\section{Results and discussion}

\subsection{Socio-demographic profile of respondents}

Table 1 shows the farmers' socio-demographic profiles. A total of 116 of the respondents were male (57.1\%), and
Table 1. Socio-Demographic Profile of Respondents $(n=203)$

Expl

\begin{tabular}{lc}
\hline Gender & $\%$ \\
\hline Male & 57.1 \\
Female & 42.9 \\
\hline Age & \\
\hline $20-29$ & 4.0 \\
$30-39$ & 23.6 \\
$40-49$ & 25.6 \\
$50-59$ & 28.6 \\
$60-69$ & 16.7 \\
$70-79$ & 1.5 \\
\hline Ethnics & \\
\hline Iban & 4.4 \\
Malay & 3.4 \\
Chinese & 4.4 \\
Bidayuh & 86.8 \\
Others & 1.0 \\
\hline Relign
\end{tabular}

Religion

\begin{tabular}{lc} 
Christian & 94.6 \\
Muslim & 4.9 \\
Others & 0.5 \\
\hline
\end{tabular}

Marital Status

Single 3.5

Married $\quad 93.0$

Divorce 3.5

Educational Background

Never been to school 20.2

Primary school $\quad 48.3$

Secondary school $\quad 31.5$

College/University 0.0

Income Status

RM0 - RM500 13.3

RM500 - RM1000 $\quad 58.6$

RM1000 - RM1500 15.3

RM1500 - RM2000 6.9

RM2000 - RM2500 2.9

RM2500 - RM3000 1.0

RM3500 - RM4000 0.5

RM4000 - RM4500 1.0

RM4500 - RM5000 0.5

Farming Experience

$0<5$ years $\quad 41.4$

$5<10$ years $\quad 17.7$

$10<15$ years $\quad 14.3$

$15<20$ years $\quad 16.3$

$20<25$ years $\quad 5.4$

$25<30$ years $\quad 3.4$

$30<35$ years $\quad 1.5$

Farm Size

Less than 1 ha 38.4

Less than 2 ha $\quad 41.4$

Less than 3 ha $\quad 15.3$

Less than 4 ha $\quad 1.9$

Less than 5 ha $\quad 3.0$

Land Ownership

\begin{tabular}{lc} 
Own & 70.4 \\
Rented & 2.0 \\
Heritage & 27.6 \\
\hline Type of Pepper & \\
\hline Belantung & 1.0 \\
Djambi & 12.3 \\
Kalluvally & 6.4 \\
Kuching/semonggok emas/semonggok perak & 80.3 \\
\hline
\end{tabular}


only $42.9 \%$ were female. The largest age group was the $50-59$ years category $(28.6 \%)$, while only $1.5 \%$ of the respondents were above 70 years old. Most of the respondents were Bidayuh with a total of $176(86.8 \%)$, followed by Iban and Chinese, with equal distribution $(4.4 \%)$ or nine respondents, respectively. Seven respondents were Malay $(3.4 \%)$, and the others comprised two respondents $(1.0 \%)$. With regards to religion, $94.6 \%$ were Christian, $4.9 \%$ were Muslim, and $0.5 \%$ were from other religions. According to marital status, most of the respondents, or 189 (93\%), were married. Meanwhile, single and divorced categories have an equal number of respondents, which is seven respondents $(3.5 \%)$ each. In terms of education level, the result indicated that $20.2 \%$ of the respondents had never been to school, $48.3 \%$ went up to primary school, while the remaining $31.5 \%$ went to secondary school. The result shows that most of the respondents had attended primary school. None of the respondents went to college or university. The highest income status was the RM500 -RM1000 category. The result also shows that the respondents' farming experience was less than 5 years in the pepper industry, which holds $41.4 \%$. Meanwhile, only $1.5 \%$ of respondents were under the $30-35$ years category of farming experience. In terms of farm size, the highest number of respondents or 84 respondents (41.4\%) fall in the group with an area of planting less than 2 hectares. Meanwhile, $20.2 \%$ planted pepper in an area between 2 and 5 hectares. The respondents' land ownership is categorised into four groups; own land $(70.4 \%)$, rented $(2.0 \%)$, taxes (none), and heritage $(27.6 \%)$. Six types of pepper were planted: Belantung, Djambi, Kalluvally, Kuching, Semonggok Emas, and Semonggok Perak. The result shows that 135 or $66.5 \%$ of the respondents prefer Kuching, Semonggok Emas, and Semonggok Perak types of pepper.

\subsection{Respondents' knowledge and environmental awareness}

Table 2 shows the respondents' information on their knowledge, awareness, and information sources towards Sustainable Agriculture Practices (SAPs), types of certification, other activities, and main challenges related to pepper cultivation. The outcome shows that $98.5 \%$ of the respondents were knowledgeable about SAPs practices, while the remaining $1.5 \%$ were unknowledgeable about the practices. However, only $50.7 \%$ of the respondents were aware of these practices, while $49.3 \%$ were still unaware. A total of 144 (70.9\%) of the respondents obtained information about SAPs from their friends, followed by family members (99 respondents, or $48.8 \%$ ). Relatives, Newspapers and Other pepper farmers show almost the same percentage; 76 respondents $(37.4 \%), 72$ respondents $(35.5 \%)$, and 71 respondents $(35.0 \%)$, respectively. Only $32 \%$ of the respondents from received information the department and $25.1 \%$ of respondents from electronic media. Only 40 respondents (19.7\%) have Malaysian Good Agriculture Practices (MyGAP) Certificate, 31 (15.3\%) have a Malaysian Organic (MyOrganic/SOM) certificate, and 54 respondents $(17.7 \%)$ possessed another certificate. All of the respondents were registered under the Malaysian Pepper Board (MPB), 48.8\% under Pertubuhan Peladang Kawasan, and 12.8\% under Jabatan Pertanian. Overall, the result shows that the respondents were registered with at least one of the agriculture agencies. Respondents were not only dependent on cultivation as their primary business; they were also involved with other activities, such as processing pepper into end product $(26.6 \%)$, as well as storing and marketing the pepper product (27.1\%). Most of the respondents, 169 (83.3\%), are interested in sustainable farming. However, they encounter some challenges, such as financial assistance, awareness, support service, and motivation $(73.9 \%)$.

Table 2. Respondent's Knowledge and Environmental Awareness $(n=203)$

\begin{tabular}{lc}
\hline Frequency (N) & Percentage (\%) \\
\hline Knowledge & 98.5 \\
Awareness & 50.7 \\
\hline Sources of Information & \\
\hline Friends & 70.9 \\
Family & 48.8 \\
Relatives & 37.4 \\
Other pepper farmers & 35.0 \\
Department & 32.0 \\
Electronic Media & 25.1 \\
Newspaper & 35.5 \\
\hline Types of Certification & \\
\hline MyGAP & 19.7 \\
MyORGANIC & 15.3 \\
Others & 17.7 \\
\hline Registered Agency & \\
\hline Malaysian Pepper Board & 100.0 \\
Pertubuhan Peladang & 48.8 \\
Jabatan Pertanian & 12.8 \\
\hline Other Activities & \\
\hline End product processing & 26.6 \\
Product packaging & 0.0 \\
Product storing & 27.1 \\
Product Marketing & 27.1 \\
\hline Main Challenges & \\
\hline Financial assitance & 73.9 \\
Awareness & 73.9 \\
Support service & 73.9 \\
Interest & 83.3 \\
Motivation & 73.9 \\
\hline
\end{tabular}


3.3 Farmers' attitude towards sustainable agriculture practices

The attitude towards the Intention to perform a behaviour is defined as a person's overall evaluation of two separate components (Ajzen, 2002). It is assumed to have two components that work together: beliefs about the consequences of the behaviour and the corresponding positive or negative judgements about each feature of the behaviour. In this study, the behavioural beliefs include the following: "I believe that implementing SAPs would help me to reduce adverse environmental impacts". Meanwhile, for the positive statement such as "I confident that SAPs could help to protect human health", "For me, adopting SAPs is meaningful" and "Adopting SAPs is a good investment". Respondents were asked twelve questions regarding why they are interested in or less interested in adopting SAPs. Overall, the mean value was in the range of more than 5.0. The respondents believed that attitude increased the likelihood of adopting SAPs. Most of the respondents indicated that they believe implementing sustainable agricultural practices (SAPs) would help to reduce adverse environmental impacts (58.1\%), and the adoption of SAPs is meaningful to them (39.9\%). More than half of the respondents $(51.2 \%)$ were confident that SAPs could help protect human health, and nearly half (44.8\%) of the respondents agreed that adopting SAPs is a good investment. About $51.2 \%$ of the respondents believe that SAPs could increase the nutrition supply and food security. The majority of the respondents $(51.7 \%)$ agreed that the implementation of SAPs would be worthwhile in producing quality products of pepper. $(45.3 \%)$ of the respondents agreed that implementation of SAPs is a wise move, and $(47.3 \%)$ believe that regular implementation of SAPs could help farmers out of the poverty zone. Most of the respondents (53.7\%) considered SAPs execution is not that complicated. The result also shows about $49.3 \%$ of respondents confirmed the application of SAPs could protect the ecosystem, such as animals, plants, water, minerals, and soil, while $52.7 \%$ of the respondents believe that SAPs could help them to maximise the profit in the long term. This part also asked respondents whether the practices are costly and complicated. The result indicates that $61.6 \%$ and $53.7 \%$ of the respondents thought SAPs are not complicated and costly to implement, respectively. Each question's mean is almost the same but highlighted more on the question "For me, adopting sustainable agricultural practices is meaningful" and "I am confident that sustainable agricultural practices could help protect human health" at 5.60 and 5.51, respectively.
3.4 Farmers' subjective norm towards sustainable agriculture practices

Eight Item construct of Subjective norms adapted from Golnaz et al. (2015) showed how particular societal attitudes have influenced the farmers to adopt SAPs. The highest mean values represented the following items: Trend (5.33), competitor (5.33), influenced by food products' policy (5.38), and lifestyle (5.33) influenced the farmers more towards SAPs. Most of the respondents (53.2\%) were encouraged by family to implement SAPs. Meanwhile, the result indicated encouragement from the respondents' friends, and the neighbourhood shared the same percentage $(52.7 \%)$. The percentage shows that the respondents agreed with "Policy regarding the food products based influence me to implement Sustainable Agriculture Practices" (50.2\%). Meanwhile, the respondents were also encouraged by relatives $(49.8 \%)$, change of trend $(48.3 \%)$, lifestyle $(47.3 \%)$, and competitors $(45.3 \%)$. The result shows that each of the subjective norms' variables has an essential role in influencing the respondents' Intention towards implementing sustainable agriculture practices (SAPs) in pepper cultivation.

\subsection{Farmers' perceived behavioural control towards sustainable agriculture practices}

Items Construct of Perceived Behavioural Control have to do with the difficulty or likelihood of performing the behaviour (Ajzen, 2002). Based on the results, most of the respondents respond to a scale of six (Agree). The respondents agreed that they could implement cultural control practices, such as pruning, drainage, and weeding $(54.7 \%)$. Meanwhile, respondents scored the same values (52.2\%) for three questions: "I am confident that good drainage management is able to maximise the growth of pepper," "I am confident that high yielding and resistant varieties of pepper influence the quality and quantity of the final product", and "I will try to keep a hygienic environment at all stages of cultivation to produce a healthy product." The respondents also agreed that they could employ soil management to control soil fertility (51.2\%). Other questions scores are: "I will use suitable procedures such as using standard rooting mixture" (49.3\%), "I will taking physical preventive measures such as removal of affected plants to prevent contamination to healthy plants" (47.3\%), "Implementation of sustainable agriculture practices help me to get government assistance" (46.3\%) "I am willing to provide the requirements needed before planting such as providing a tree supports, standard spacing, land preparations, and cover crops to increase the productivity $(45.8 \%)$ and "I will provide shading at the nursery stage to ensure the pepper tree remains healthy before 
transplanting to the field" (44.3\%). Under the scale of five (Somewhat agree), the respondents thought they could implement SAPs to control environmental pollution $(47.8 \%)$. Also, the respondents are confident that suitable selection influence the growth rate of pepper (47.80), the respondents will ensure the right amount of pesticides used to protect the ecosystem $(47.3 \%)$, and the respondents will apply biological control at the first line to control pest and disease when incidence noticed and where the appropriate bio-control agent is available $(45.8 \%)$.

\subsection{Farmers' intention towards sustainable agriculture practices}

In the first statement, the questions asked whether respondents have an intention to implement SAPs to increase the quality of pepper products. The Five Items construct of Intention were adapted from Golnaz et al. (2015). A significant portion of respondents $(51.7 \%)$ agreed that they were very likely to plan to practice sustainable agriculture to improve the product's nutrition supply and food security. About 50.2\% of the respondents stated that they would implement SAPs to minimise the environmental effect. Meanwhile, about $48.8 \%$ of the respondents intend to implement SAPs to meet customers' demand for the product's high quality. About $48.3 \%$ of the respondents agreed they were likely to implement SAPs to reduce and avoid the use of hazardous substances and be concerned about society's health. Most of the respondents (46.8\%) stated that they plan to implement SAPs to increase pepper quality (46.3\%). Approximately $45.8 \%$ of the respondents stated that they must implement SAPs to reduce farming costs, and $45.3 \%$ were more likely to implement SAPs to maximise the long-term profit. The result shows positive feedback from the respondents with mean values for all statements ranging between 5.0 and 6.0 (5.0=Likely, and $6.0=$ Very likely). Therefore, it can be summarised that most of the respondents intend to implement sustainable agriculture practices in pepper cultivation

\subsection{Factor analysis}

In this study factor analysis was used to reduce the data and identify a small number of factors that explain most of the variance observed in a much larger number of manifest variables. The results showed five-factor solutions with eigenvalues greater than 1.0 and the total variance explained was $70.442 \%$ of the total variance. As shown in Table 3, the value of KMO to measure sampling adequacy was 0.869 and indicated sufficient intercorrelations. While Bartlett's Test of Sphericity was significant (Chi square $=5342.249, \mathrm{p}<0.00$ ). The criteria used by Igbaria et al. (1995) to identify and interpret factors were: each item should load 0.50 or greater on one factor and 0.35 or lower on the other factor. The factor loadings ranged from. 0.627 to 0.832 which achieved the required range as stated by Hair et. al. (2010). Five factors indicated the farmers' Intention towards SAPs as shown in Table 4, namely; attitude, subjective norms, perceived behavioural control and intention (quality) and intention (benefits).

Table 4 presents the factor loadings from principal component factor analysis, using a varimax rotation of the respondents' responses to the 63 questions relating their Intention to implement sustainable agriculture practices (SAPs) in pepper cultivation. The results discovered four latent factors that influence the respondents' Intention to practice SAPs. The total cumulative variance explained from the exploratory factor analysis in this study was $70.442 \%$, represented by four underlying factors. Thus, the value of $70.442 \%$ of the respondents' total variation suggested that they are likely to have the Intention to implement SAPs.

The attitude towards implementing SAPs is determined as the first factor. This factor has four subvariables, with a total variance of $13.554 \%$. The four sub -variables are: 'I believe that implementing SAPs would help me reduce adverse Environmental impacts (0.811), 'I am confident that SAPs could help to protect human health' (0.751), 'For me, adopting SAPs is meaningful' (0.734), and 'Adopting SAPs is a good investment' (0.667). Subjective norms effects in the Intention to implement SAPs are the second factor, with all eight of the sub-variables total variance of $27.912 \%$.

Meanwhile, perceived behavioural control in the Intention to implement SAPs is the third factor, with a total variance of $12.502 \%$. It comprises four subvariables: 'I will provide shading at the nursery stage to ensure the pepper tree remains healthy prior to transplanting to the field' (0.766), 'I will employ soil management to control soil fertility' (0.722), 'Implementation of SAPs help me get government assistance' (0.698), and 'I am confident that good drainage management can maximise the growth of pepper (0.646).

The Intention of farmers towards implementing

Table 3. KMO and Bartlett's Test

Kaiser-Meyer-Olkin 0.869

Measure Sampling of Adequacy

Bartlett's Test of Sphericity

Approx. Chi-square 5342.249

Df

903

Significance 0 
Table 4. Respondent's Intention To Implement SAPs in Pepper Cultivation

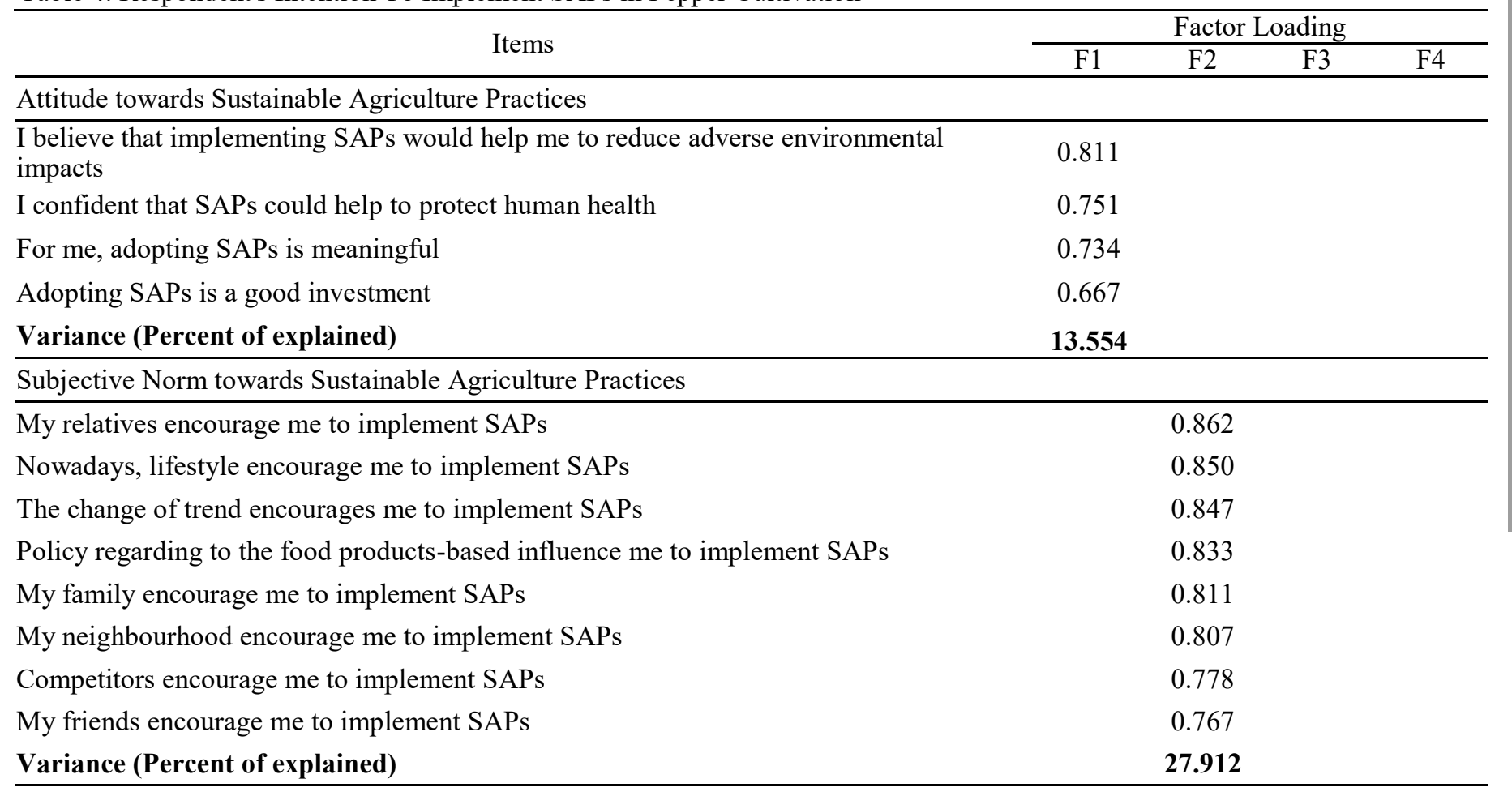

Perceived Behaviour Control Sustainable Agriculture Practices

I will provide shading at the nursery stage to ensure the pepper tree remain Healthy prior

to transplanting to the field

0.766

I will employ soil management to control soil fertility

0.722

Implementation of SAPs help me to get government assistance

0.698

I am confident that good drainage management is able to maximise the growth of pepper

0.646

Variance (Percent of explained)

$\mathbf{1 2 . 5 0 2}$

Intention towards Sustainable Agriculture Practices (Quality)

I intent to implement SAPs to increase the quality of pepper product

0.787

I want to implement SAPs to meet customer demands on high quality of product in the

market

Variance (Percent of explained)

0.770

Intention towards Sustainable Agriculture Practices (Benefit)

I wish to implement SAPs because I concern about the health of society

8.771

I try to implement SAPs to maximize my long-term profit

0.816

Variance (Percent of explained)

0.741

7.703

Total Percentage of Variance

70.442

SAPs is identified as the fourth factor, with a total variance of $16.474 \%$. There are four sub-variables under this factor; two variables are based on (quality) with a variance of $8.771 \%$, and another two variables are based on (benefit) with a variance of $7.703 \%$. This factor indicates that farmers intend to implement SAPs to improve the quality of pepper; 'I intend to implement SAPs to increase the quality of pepper product' (0.787), and 'I want to implement SAPs to meet customer demands on the high quality of products in the market' (0.770). Farmers also intend to implement SAPs to attain the benefits; 'I wish to implement SAPs because I am concerned about the health of society' (0.816), and 'I try to implement SAPs to maximise my long term profit' (0.741).

Gliem et al. (2003) asserted that Cronbach's Alpha measured internal consistency reliability among most individuals in their research. Thus, in this study, Cronbach's Alpha was applied to indicate the reliability of 20 relevant variables used in the exploratory factor analysis. This study indicates four latent factors with adequate internal reliability consistency, as indicated by Cronbach's Alpha scores in Table 5, which are attitude (0.817), subjective norms (0.935), and perceived behavioural control (0.754), and Intention (quality) (0.804), and Intention (Benefit) (0.712).

The overall findings show that there is a high intention of pepper farmers towards SAPs. Approximately, $30 \%$ of them have obtained MyGAP and Myorganic as one of the important indicators towards 
SAPs. The awareness to implement SAPs because they believe implementing sustainable agricultural practices (SAPs) would help to reduce adverse environmental impacts, indicate that they have a positive response towards adopting the SAPs in the near future. The results of the factor analysis in this study have shown all the factors that influenced the pepper farmers entrepreneurs' Intention to implement SAPs in pepper cultivation activities. These include attitude, subjective norms, perceived behavioural control and Intention (Quality) and Intention (Benefits). Typically, highly favorable behavior, subjective norms, and perceived behavioral control significantly influence a person's intention to perform a specific behavior. The pepper farmers may begin to have the initiative to adopt SAPs because they believe that SAPs, together with the innovation of technology, play a pivotal role in farm productivity advancement and enhancing food security and economic growth (Kassie et al., 2013). Besides improving soil fertility, reducing the risk of drought and water shortage, reducing erosion, and maintaining biodiversity and agroecosystem resilience (Price and Leviston, 2013) drive farmers' intention towards SAPs. Sustainable agriculture reduces input used that is potentially harmful to the environment (Wezel et al., 2014).

In order to adopt SAPs, awareness and knowledge are crucial. However, the success probability in adopting SAPs is less likely to be achieved by the farmers alone. Challenges, such as financial and support assistance are the areas that farmers needed. As one of the prominent worldwide pepper producers, Malaysian governments' roles in creating awareness, interest, and motivation among smallholder farmers to adopt sustainable agriculture practices are crucial. Strategic actions by providing grants and other assistance to the farmers will help them adopt the practices. The government also needs to focus on data management, farmer mobilisation, and develop policies and the regulatory framework. On top of that, farmers need to be ready with the transformation by preparing themselves with the latest information, knowledge, and technology to implement SAPs. Future studies would be interesting if possibly further investigate and focused on the effectiveness of the public campaigns concerning sustainable agriculture practices. It could help determine the extent to which sustainable agriculture practices campaign to raise pepper farmers' intentions to perform the practices. Hence, serious efforts should be taken to encourage the farmers' participation in implementing sustainable agriculture practices.

\section{Acknowledgement}

The researcher would like to thank the Ministry of
Higher Education, Malaysia, for the Mybrain15 scholarship and to the Malaysian Pepper Board (Sarawak Branch) for providing useful information regarding the study.

\section{References}

Ajzen, I. (1985). From intentions to actions: A theory of planned behaviour. In Kuhl, J. and Beckmann, J. (Eds.) Action control SSSP Springer Series in Social Psychology. Berlin, Germany: Springer. https:// doi.org/10.1007/978-3-642-69746-3_2

Ajzen, I. (2002). Perceived behavioural control, selfefficacy, locus of control, and the Theory of planned behaviour. Journal of Applied Social Psychology, 32 (4), 665-683. https://doi.org/10.1111/j.15591816.2002.tb00236.x

Ajzen, I. (2005). Attitudes, personality, and behaviour. $2^{\text {nd }}$ ed. United Kingdom: Open University Press.

Arvola, A., Vassallo, M., Dean, M., Lampila, P., Saba, A., Lahteenmaki, L. and Shepherd, R. (2008). Predicting intentions to purchase organic food: the role of affective and moral attitudes in the Theory of Planned Behaviour. National Library of Medicine, 50(2-3), 443-454. http://doi:10.1016/ j.appet.2007.09.010

Future Market Insight (2014). Black Pepper Market. Retrieved from Future Market Insight website: http:// www.futuremarketinsights.com/reports/black-pepper -market

Gliem, J.A. and Gliem, R.R. (2003). Calculating, interpreting, and reporting Cronbach's alpha reliability coefficient for Likert-type scales, presented at the 2003 Midwest Research-to-Practice Conference in Adult, Continuing, and Community Education. Columbus, Ohio, USA: Ohio State University.

Golnaz, R., Viduriati, S., Zainalabidin, M., Mad, N.S. and Juwaidah, S. (2015). Implementing green practices as sustainable innovation among herbalbased SME entrepreneurs. Journal of Food Products Marketing, 22(1), 1-18. https:// doi.org/10.1080/10454446.2015.1048030

Hossein, B., Yazid, A. and Zeinab, S. (2014). Antioxidant activity of Piper nigrum L. essential oil extracted by supercritical $\mathrm{CO}_{2}$ extraction and hydrodistillation. Talanta, 121, 220-228. https:// doi.org/10.1016/j.talanta.2014.01.007

Jamal, O. and Yaghoob, J. (2014). Selected research issues in the Malaysian agricultural sector. Jurnal Ekonomi Malaysia, 48(2), 127-136. https:// doi.org/10.17576/jem-2014-4802-11

Kaiser, F.G., Hubner, G. and Bogner, F. (2005). 
Contrasting the Theory of planned behaviour with the value-belief-norm model in explaining conservation behaviour. Journal of Applied Social Psychology, 35(10), 2150-2170. https:// doi.org/10.1111/j.1559-1816.2005.tb02213.x

Kusairi, M.N. and Fatimah, M.A. (2009). Malaysian farm certification scheme for good agricultural practices. Impak. Retrieved from website: http:// econ1.upm.edu.my/ fatimah/KMN\%20FMA\% 20GAP\%20Impak\%20DoE\%202009.pdf

Price, J.C. and Leviston, Z. (2014). Predicting proenvironmental agricultural practices: The social, psychological and contextual influences on land management. Journal of Rural Studies 34, 65-78. https://doi.org/10.1016/j.jrurstud.2013.10.001

Singh, A.S. and Masuku, M.B. (2014). Sampling techniques and determination of sample size in applied statistics research: An overview. International Journal of Economics, Commerce and Management. 2(11), 1-22.

Wezel, A., Casagrande, M., Celette, F., Vian, J.F., Ferrer, A. and Peigné, J. (2014). Agroecological practices for sustainable agriculture. A review. Agronomy for sustainable development, 34, 1-20. https://doi.org/10.1007/s13593-013-0180-7 